\title{
Vibration effect of tunnel surrounding rock under cyclic blasting excavation
}

\author{
Guosheng Zhong ${ }^{1, a}$ and Dinghuan Liu ${ }^{1, b}$ \\ ${ }^{1}$ School of Architecture \& Civil Engineering, Huizhou University, Huizhou, 516007, China \\ a70371482@qq.com, b41702440@qq.com
}

\begin{abstract}
Keywords: Cyclic blasting loading; Tunnel excavation; Vibration effect
Abstract: Model test studies based on the similarity theory was conducted to solve the problem of vibration effect of tunnel surrounding rock under push-type cyclic blasting excavation. The model was constructed with a ratio of 1:15. By simulating the tunnel excavation of push-type cyclic blasting, the influence of the change of blasting parameter on vibration effect was explored. The relationship between the damage evolution of surrounding rock and blasting times was established. The following test results can be obtained: When the maximum section dose was roughly same, the influence of the initiation section number on the dielectric coefficient $(K)$ of Sodev formula was very small, and on the contrary to the attenuation coefficient of Sodev formula.
\end{abstract}

\section{Introduction}

Drilling blasting is a common and efficient construction method for excavation, tunnel excavation, underground chamber construction and other engineering rock mass excavation. During the excavation of rock mass engineering, it is inevitable to have a negative impact on the surrounding rock mass. The vibration effect caused by the circulating blasting, which leads to the rapid release of the stress in the surrounding rock, inevitably damages the surrounding rock, and makes the mechanical parameters of the surface rock mass decrease greatly. Blasting vibration may cause rock to retain the local crack and destabilization, and blasting relaxation zone formation may also aggravate rock subsequent unloading charge relaxation effect. There are hidden dangers to the safety construction and normal operation of the project.

Many scholars at home and abroad have studied the problem of surrounding rock damage caused by blasting operation, and have carried out fruitful research work [1,2]. However, the above researches of rock mass damage caused by blasting loading were put forward and realized mostly in the case of single hole charge blasting or repeated blasting under single hole charge, so it is not consistent with the actual blasting operation in rock mass engineering. Actual rock engineering excavation, such as mining, tunnel excavation, underground chamber construction, is a push-type reciprocating multi delay blasting operation. Therefore, it is necessary to study in depth and systematic the vibration effect of surrounding rock.

\section{Similar material model test plan}

\section{Model scale and similar material model design}

According to the actual size of the copper mine roadway excavation section, and the indoor test site space, the test model scale was finally determined as $1: 15$. The test model scale is in full compliance with the requirements of the similar theory $(1: 20 \sim 1: 4)$ [3]. Therefore, according to the test model scale, the model size was determined as $3000 \mathrm{~mm} \times 3000 \mathrm{~mm} \times 2500 \mathrm{~mm}$. Natural quartz sand and gravel of particle size $2-4 \mathrm{~cm}$ were chosen as the aggregate of the similar material model. Reference to China's current concrete mix design procedures [4], the similar materials with compressive strength $31.1 \mathrm{MPa}$ and elastic modulus $29.3 \mathrm{GPa}$ were made from the portland cement with compressive strength $32.5 \mathrm{MPa}$, and it was used to simulate the surrounding rock of limestone. 


\section{Scheme design of blasting operation}

According to the similarity theory [3], the blasting damage test of similar material model should be in accordance with the way of the push-type cyclic blasting excavation of the tunnel. Each cycle of blasting operation all includes the blasting form of the cutting hole, caving hole and periphery hole in this model test. The length of one cycle of blasting excavation is about $300 \mathrm{~mm}$. Four cycles of blasting excavation are carried out, so there are twelve blasting operations. In this test, the total length of the tunnel blasting excavation is about $1200 \mathrm{~mm}$.

The section size of the simulating tunnel excavation is determined by the test model scale. The blasting holes arrangement of the tunnel excavation section is as follows: the inside ring, middle ring, and outer ring are the cutting hole, caving hole, and periphery hole, respectively. The blasting order is the first cutting hole, then caving hole, the last periphery hole, and the blasting is delayed initiation mode, shown in Fig.1. After four cycles of blasting excavation, that is, a total of twelve blasting operations, the photograph of the tunnel blasting excavation for model test is shown in Fig.2.

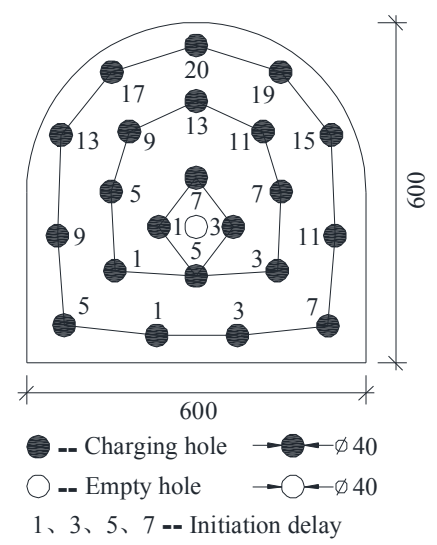

Fig.1 Tunnel section size and blasting hole layout

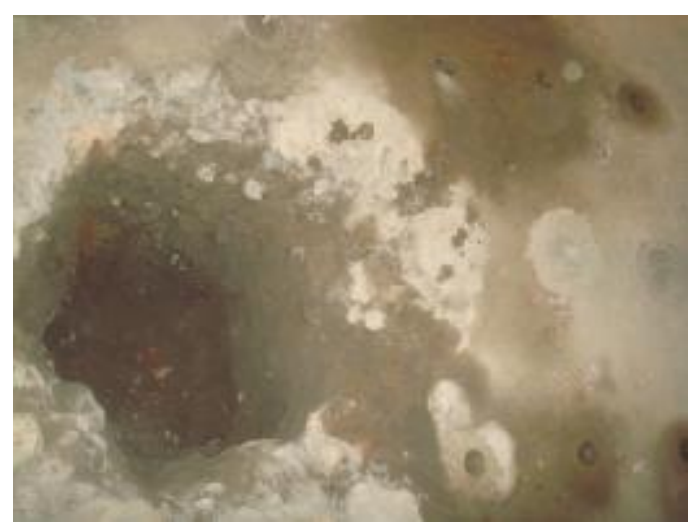

Fig.2 Tunnel blasting excavation for model test

Emulsion explosive is used in the test. In order to improve the blasting effect, the charge mode is a coupled charge. When charging the explosive, the explosive is pressed into the bottom of the hole, and pressed close to the hole wall. The clay is used to block the hole, and the blockage length is about $150 \sim 200 \mathrm{~mm}$. The blasting of the cutting hole, caving hole, and periphery hole is used to delay initiation in the model test. According to the similar theory and the tunnel excavation section size, the numbers of the millisecond delay initiation for the cyclic blasting operation can be determined, and the specific blasting parameters are shown in Table 1.

Table 1 The blasting parameters of circulation blasting operation of tunnel model

\begin{tabular}{|c|c|c|c|c|c|}
\hline Blasting hole name & $\begin{array}{l}\text { Excavation length } \\
/ \mathrm{mm}\end{array}$ & $\begin{array}{c}\text { Initiation delay } \\
\text { time }\end{array}$ & $\begin{array}{l}\text { Initiation charge } \\
\qquad / \mathrm{g}\end{array}$ & $\begin{array}{l}\text { Total charge } \\
\text { /g }\end{array}$ & Charge mode \\
\hline Cutting hole & 300 & $1,3,5,7$ & $50,50,55,55$ & 210 & Coupling \\
\hline Caving hole & 300 & $\begin{array}{l}1,3,5,7 \\
9,11,13\end{array}$ & $\begin{array}{c}50,50,50 \\
50,55,55,60\end{array}$ & 370 & Coupling \\
\hline Periphery hole & 300 & $\begin{array}{c}1,3,5,7,9,11 \\
13,15,17,19,20\end{array}$ & $\begin{array}{c}55,55,60,60,55 \\
55,60,60,55,55,60\end{array}$ & 630 & Coupling \\
\hline
\end{tabular}

\section{Scheme design of test measuring}

The blasting vibration testing of the model test is carried out by the BlastmateIII blasting vibration recorder, produced in Canada. The instrument has the characteristics of wide detection frequency band, large measurement range and high precision, and its speed sensor is the three-direction earthquake detector. During the testing, the speed sensor is arranged in the center of each acoustic wave testing section, and there is a total of 6 units, as shown in Fig.3. In order to improve the effect of blasting 
vibration monitoring, the speed sensor is fixed firmly on the model by the expansion bolt. The photograph of blasting vibration testing of test site is shown in Fig. 4.

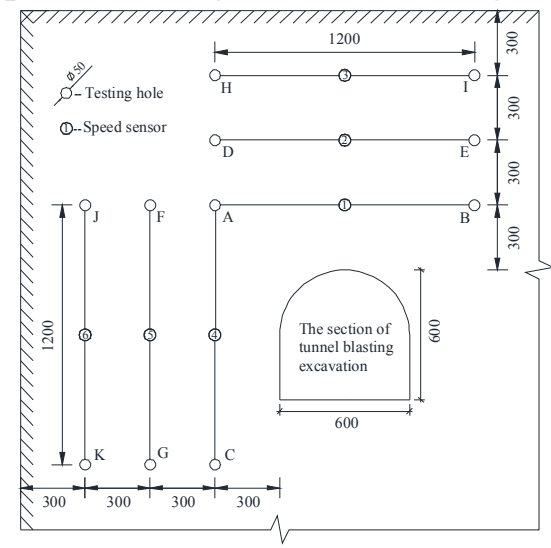

Fig.3 Layout of measuring points of the model test

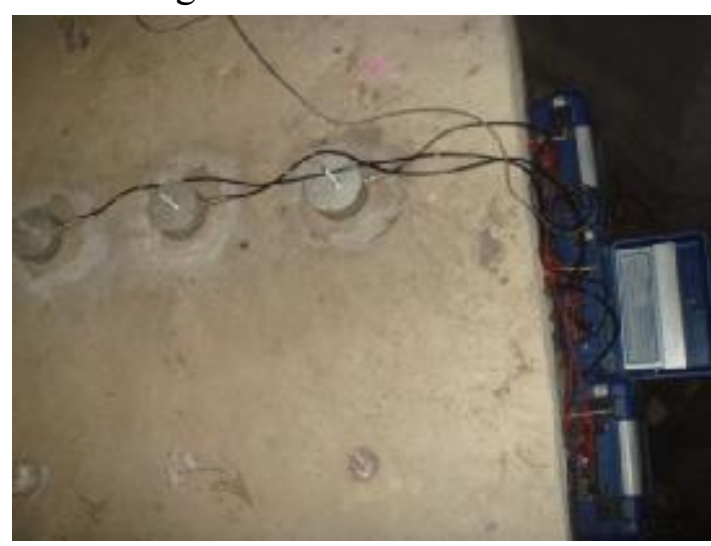

Fig.4 Blasting vibration testing of model test

\section{Testing results and analysis}

According to the relevant research shows that [5]: the particle vibration in the medium caused by the explosive explosion has vertical, radial and tangential velocity components; In the case of the smaller altitude difference and close distance, the vertical velocity component plays a controlling role in the blasting vibration. Therefore, the vertical particle vibration velocity is chosen as the monitoring physical quantity in this essay.

The tunnel blasting excavation adopts the cutting hole, caving hole, and periphery hole blasting operation sequence in the model test, and vibration monitoring is carried out for each blasting operation. Typical blasting vibration time-history curves are generated by three kinds of blasting operation, as shown in Fig.5.

There are respectively 4,7 and 11 peaks in the blasting vibration time-history curves of the cutting hole, caving hole, and periphery hole, as seen from Fig.5. The delay blasting effect is very obvious, which is completely corresponding with the initiation detonator delay distribution listed in Table 1 .
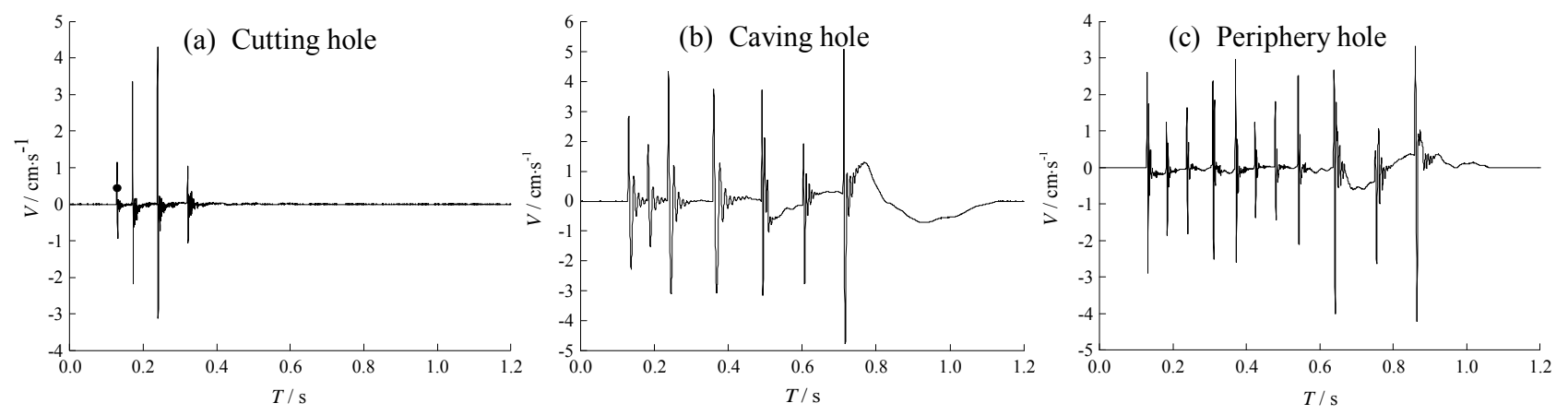

Fig.5 Blasting vibration curve of cyclic blasting excavation

Table 2 The related data of blasting vibration monitoring

\begin{tabular}{|c|c|c|c|c|c|}
\hline Measuring point & $\begin{array}{c}\text { Distance from } \\
\text { blast center / m }\end{array}$ & Blasting type & $\begin{array}{c}\text { Number of } \\
\text { delay / } \mathrm{n}\end{array}$ & $\begin{array}{l}\text { Main vibration } \\
\text { frequency / Hz }\end{array}$ & $\begin{array}{l}P P V \\
/ \mathrm{cm} \cdot \mathrm{s}^{-1}\end{array}$ \\
\hline \multirow{3}{*}{ (1),(4) } & \multirow{3}{*}{0.6} & Cutting blasting & 4 & $137 \sim 162$ & $6.14 \sim 7.62$ \\
\hline & & Caving blasting & 7 & $153 \sim 192$ & $6.07 \sim 7.51$ \\
\hline & & Periphery blasting & 11 & $201 \sim 258$ & $6.02 \sim 7.78$ \\
\hline \multirow{3}{*}{ (2),(5) } & \multirow{3}{*}{0.9} & Cutting blasting & 4 & $105 \sim 141$ & $4.03 \sim 5.21$ \\
\hline & & Caving blasting & 7 & $117 \sim 149$ & $4.38 \sim 5.62$ \\
\hline & & Periphery blasting & 11 & 161 201 & $4.17 \sim 5.55$ \\
\hline (3),6) & 1.2 & Cutting blasting & 4 & $41 \sim 85$ & $1.82 \sim 3.29$ \\
\hline
\end{tabular}




$\begin{array}{cccc}\text { Caving blasting } & 7 & 68 \sim 111 & 2.08 \sim 3.62 \\ \text { Periphery blasting } & 11 & 85 \sim 143 & 2.22 \sim 3.56\end{array}$

The related data of blasting vibration monitoring of the cutting hole, caving hole, and periphery hole blasting operations under push-type cyclic blasting excavation are shown in Table 2.

The analysis from Table 2 shows that: In the same geological environment and distance from blast center, the number of delay initiation is more, the higher the main vibration frequency of blasting seismic wave; In the same delay blasting, the distance from blast center is longer, the lower the main vibration frequency of blasting seismic wave. The peak particle vibration velocity depends on the maximal delay dose and the distance from blast center, and is in conformity with Sodev formula, as shown in Formula (1).

$$
V=K\left(\frac{\sqrt[3]{Q}}{R}\right)^{\alpha}
$$

Where $V$ is the peak particle vibration velocity $\left(\mathrm{cm} \cdot \mathrm{s}^{-1}\right) ; K$ is the dielectric coefficient; $Q$ is the maximal delay dose $(\mathrm{kg}) ; R$ is the distance from blast center $(\mathrm{m}) ; \alpha$ is the attenuation coefficient.

According to the relevant research shows that [6]: Because the delay blasting method is adopted in the tunnel blasting excavation, the distance between the initiation point and the measuring point should be replaced by the equivalent distance. The calculation formula of the equivalent distance and the maximal equivalent delay dose can be expressed as:

$$
\begin{aligned}
R^{\prime} & =\frac{\sum_{i=1}^{n}\left(\sqrt[3]{q_{i}} r_{i}\right)}{\sum_{i=1}^{n} \sqrt[3]{q_{i}}} \\
Q^{\prime} & =\sum_{i=1}^{n} q_{i}\left(\frac{R^{\prime}}{r_{i}}\right)^{3}
\end{aligned}
$$

Where $R^{\prime}$ is the equivalent distance $(\mathrm{m}) ; Q^{\prime}$ is the maximal equivalent delay dose $(\mathrm{kg}) ; q_{i}$ is the charge dose of the $i$ hole $(\mathrm{kg}) ; r_{i}$ is the distance between the $i$ hole and the measuring point (m).

According to the monitoring data of blasting vibration, the equivalent distance and the maximal equivalent delay dose of all measuring points under each blasting are respectively calculated by the Formula (2) and (3). Using Formula (1), the linear regression analysis of the monitoring data of different number of delay is carried out by the least square method, and the dielectric coefficient $K$ and attenuation coefficient $\alpha$ of Sodev formula and the correlation coefficient $\gamma$ of linear regression analysis can be determined, shown in Table 3. With blasting monitoring data of four initiation delays as an example, the linear regression analysis is shown in Fig.6.

From the analysis of Table 3, it is known that the influence of number of delay on the attenuation coefficient $\alpha$ of Sodev formula is very large, on the contrary to the dielectric coefficient $K$ of Sodev formula. The main reason is that: In the same geological environment, the number of delay initiation is more, the main vibration frequency of blasting seismic wave is higher, and the attenuation of high frequency signal in the rock and soil is faster. In addition, the blasting vibration effect analysis is carried out according to the blasting monitoring data of the same number of delay, and the correlation is better. Therefore, the influence of number of delay on blasting vibration effect can not be ignored. 


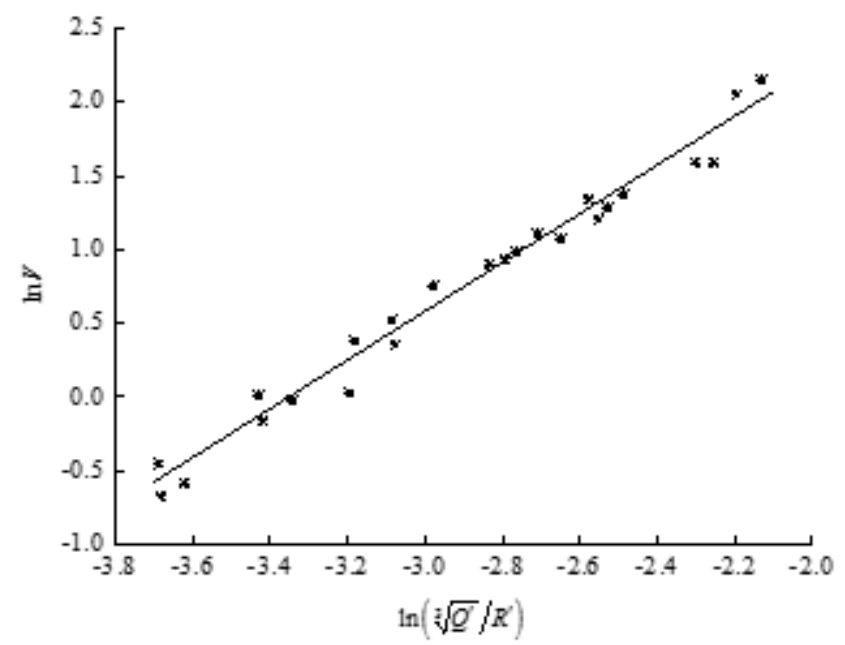

Fig.6 Linear regression analysis of blasting vibarion data of four initiation delays

Table 3 The parameters of linear regression analysis of blasting vibration monitoring data

\begin{tabular}{cccc}
\hline $\begin{array}{c}\text { Number of delay } \\
/ n\end{array}$ & $\begin{array}{c}\text { Dielectric coefficient } \\
/ K\end{array}$ & $\begin{array}{c}\text { Attenuation coefficient } \\
/ \alpha\end{array}$ & \multicolumn{2}{c}{ Correlation coefficient } \\
\hline 4 & 108.42 & 1.2539 & 0.9435 \\
& & Fig.6 Linear regression analysis of blasting \\
& & vibarion data of four initiation delays \\
7 & 109.25 & 1.3673 & 0.9541 \\
11 & 106.63 & 1.6145 & 0.9369 \\
$4,7,11$ & 107.86 & 1.3841 & 0.8523 \\
\hline
\end{tabular}

\section{Conclusion}

In the cyclic blasting operation of tunnel excavation, the blasting parameters design not only controls the maximal delay dose, but also pay attention to the influence of the number of initiation delay on blasting vibration effect. When the maximum section dose was roughly same, the influence of the initiation section number on the dielectric coefficient $(K)$ of Sodev formula was very small, and on the contrary to the attenuation coefficient $(\alpha)$ of Sodev formula. The reasonable initiation delay can gain better rock mass breaking effect, and to control the stability of surrounding rock. When analyzing the influence of blasting vibration on surrounding rock damage, the influence of number of delay on blasting vibration effect can not be ignored.

\section{Acknowledgements}

This work was financially supported by the National Natural Science Foundation of China (51064009), the Natural Science Foundation of Guangdong Province of China (2016A030313121), the Higher School Talent Introduction Project of Guangdong Province (A413.0210) and the Science \& Technology Project of Huizhou City of Guangdong Province of China (2014B020004018). 


\section{References}

[1] Xiang Xia, Junru Li, Haibo Li, et al. Study on damage characteristics of rock mass under blasting load in ling'ao nuclear power station, guangdong province [J]. Chinese Journal of Rock Mechanics and Engineering, 2016, 35(12): 2510-2517.

[2] Guohua Zhang, Libiao Chen, Xiang Xia, et al. Numerical simulation and experimental study of damage range of surrounding rock in large tunnel under blasting excavation [J]. Chinese Journal of Rock Mechanics and Engineering, 2015, 34(8): 1610-1619.

[3] Guangxin Cui. Similarity theory and model test [M]. Xuzhou: China University of Mining and Technology Press, 2016.

[4] The Professional Standards Compilation Group of People's Republic of China. Specification for mixture ratio design of common concrete (JGJ55-2011) [S]. Beijing: China Architecture and Building Press, 2011.

[5] Guosheng Zhong, Liping Ao, Kui Zhao. Influence of explosion parameters on wavelet packet frequency band energy distribution of blast vibration [J]. Journal of Central South University, 2012, 19(9): 2674-2680.

[6] Renliang Shan, Liwei Song, Yao Bai, et al. Model test studies of damage evaluation of frozen rock wall under blasting loads [J]. Chinese Journal of Rock Mechanics and Engineering, 2014, 33(10): 1945-1952. 